\title{
In Search of a Social Master Frame for Energy Transition ${ }^{1}$
}

Giorgio Osti, University of Padua, Italy

Email g.osti@unipd.it

Orcid 0000-0002-6014-3113

Abstract. The paper aims to illustrate the different roles that social sciences can play in the study of the energy transition. To this end, a scheme is developed that frames the relative position of the social sciences with respect to other disciplines (metaframe). Secondly, socialization is identified as a charismatic category capable of providing an original, typically sociological contribution to the complex and hesitant energy transition (masterframe)

Key words: energy, transition, socialisation, meta frame, master frame

The paper aim is to justify and frame the contributions social sciences can provide to energy question. A general discourse on the social aspect of energy issues could start from different angles. A first angle could be a bibliographic review of the enormous scientific production of social sciences in the energy field. The humanities and social studies have grown exponentially. This type of analysis is facilitated by the digitization of papers and many times is based on content analysis. Some people are doing it very well (see Dunlop 2019; Ingeborgrud et al. 2020). A second angle could start with a plea for giving more space and weight to the social sciences in decision-making arenas or interdisciplinary research groups (see Spreng D. et al. 2012). We often complain about the ancillary role of sociology in teams that have to plan large public works or smart cities. Finally, a third angle could be an effort to identify crucial concepts and theories that can shed light on the complex energy transition we are experiencing (Sovacool, Hess 2017; Sovacool et al. 2020). We have a tremendous need for powerful theories that are useful to pierce reality, easily communicable outside social sciences and also that help people to make sense. This last term refers to sensations, significance, direction; they are basic ingredients of every social research. This last angle will be privileged in the paper.

We have as social researchers a compelling need for alluring concepts and theories useful for understanding and communicating to the public the complexities of energy issue. The purpose here is therefore two-fold. First, we must seek a sufficiently broad and insightful framework, a meta-frame, to simplify and include specific research paths. This task can be defined as 'analytical', that is, identifying meta-categories that can contain multiple perspectives for analysis. Second, we must inquire into a master-frame originating from within the social sciences, a frame capable of arousing the enthusiasm to expose or uncover unknown or original concepts or ideas never before studied. This second task is more heuristic, what we can call a 'search for a charismatic interpretative category' specific of social sciences.

\footnotetext{
${ }^{1}$ This paper is a revised version of the speech given at the first plenary session of the 'Energy and Society' conference held at the University of Trento on 10-12 February 2021; https://webmagazine.unitn.it/en/evento/sociologia/71352/fifth-energy-and-society-conference.
} 
Presented here is a play on words between the two types of frames. The former, the metaframe, simply indicates a concept capable of containing others. The latter, the master-frame, is more ambitious and claims to be a discourse that motivates, guides and innovates. In the cognitive sociological literature, 'master frame' indicates a configuration of reality capable of profoundly modifying social structures (Benford 2013). Such was, for example, the idea in the 1980s that ecological thinking would modify the then-dominant labour-capital divide (Eder 1990). But before seeking out a master frame, it is important to illustrate the meta-frame as presented in Table 1, which represents the fulcrum of the analytical proposal.

\section{Table 1}

Social Sciences Position Relative to Energy Engineering and Management Disciplines, According to Key Words and Approaches*

\begin{tabular}{|l|l|l|}
\hline \multirow{2}{*}{ Social sciences position (and } & \multicolumn{2}{|c|}{ Key words (approaches) } \\
\cline { 2 - 3 } analytical level) & \multicolumn{1}{|c|}{ Mechanisms } & \multicolumn{1}{|c|}{ Reflexivity } \\
\hline ABOVE (macro) & $\begin{array}{l}\text { Material Interests, power } \\
\text { asymmetry (political ecology) }\end{array}$ & $\begin{array}{l}\text { Cognitive Frames (social } \\
\text { constructivism) }\end{array}$ \\
\hline IN BETWEEN (meso) & $\begin{array}{l}\text { Organisational Borders (neo- } \\
\text { institutionalism) }\end{array}$ & $\begin{array}{l}\text { Bridges among systems } \\
\text { (network analysis) }\end{array}$ \\
\hline BELOW (micro) & $\begin{array}{l}\text { Behaviours (ABC model, } \\
\text { nudge approach) }\end{array}$ & $\begin{array}{l}\text { Games (strategic studies, } \\
\text { reasoned action) }\end{array}$ \\
\hline
\end{tabular}

Note. 'Approaches' in the sense of 'paradigm' (Boudon and Bourricaud, 1991, p. 532)

Table 1 frames the position of the social sciences with respect to other forms of knowledge in the field of energy. This scheme should apply to various environmental resources in addition to energy, such as water, soil and ecosystems.

Table 1 will seem very theoretical, but it arises from a practical need proposed by Osti (2019) to relate to fellow scholars of the physical, engineering and medical sciences the many opportunities for collaborative work in universities, research centres and planning teams. First, it is important to reinforce the idea that the relationship of the social sciences with the physicalmathematical-engineering sciences is mobile and variable, not unique. This reassures us that there is no fixed, constant ranking between disciplines, that there are no disciplines of first class and second class. The detestable prestigious academic rankings exist, but they are relative. Second, it is important to notice that there is a meso, an intermediate level between the macro and the micro (Hara et al., 2012; Reid et al., 2010; Schenk et al., 2007). This has been known for some time: you will remember Robert Merton's medium range theories. But it is only during the relational turn of the last few decades that the meso level has embraced the social sciences (Dépelteau, 2013). Such a 
level is not the solution of agency-structure dilemma ${ }^{2}$. Moreover, note that the first column not only collects the level of analysis, but also the relative position of the social sciences with respect to the others. In other words, they are two criteria put together. Also in table 1, columns 2 and 3 indicate two basically polar trends: mechanisms and reflexivity. The former indicates emerging impersonal qualities of a social aggregate, the latter indicates processes that pass through a certain awareness of the actors. This classification refers to the classic dichotomy of sociology - actor-system - already mentioned.

The position above, that is, when the social sciences are placed at an analytical level higher than that of other knowledges, is represented by two well-known models of analysis: political ecology and the frame approach. Following Bridge et al. (2018), these models claim the interpretation of technical-physical phenomena within a precise scheme, political ecology, that of the unbalanced conflict between material interests and the resulting asymmetry of power: in their text Bridge et al. effectively summarize the matter thus 'We outline a political ecology perspective on EU energy policy that illuminates how the distribution of social power affects access to energy services, participation in energy decision-making and the allocation of energy's environmental and social costs'.

The framing approach is on the same analytical and positional level. Events, even of a very technical nature, must be inserted into 'finite provinces of meaning' (Shütz 1962), conceptual frameworks that allow understanding. Thus, some technological packages become attractive or rejected according to the cognitive frame that is adopted. For example, the evaluation of the wind farm changes depending on whether it is within the landscape frame or the 'renewable' label or whether it is within a top-down or bottom-up perspective in decision making. The frame per definition is always around the issue; in that sense, it is above, a level of knowledge able to contain another one.

To give a further example of the 'above' approach, we can use two controversial Dutch cases, one project concerning shale gas extraction and the second about the capture of $\mathrm{CO}_{2}$ as studied by Pesch et al. (2018). The authors identify three types of justice claims concerning both projects: distributive, procedural and based on recognition. The claim based on the struggle for recognition of local public resistance (that entails dignity, respect, identity, etc.) is the most neglected, but it is of high efficacy for both an understanding of the events and the capacity to mobilise people. In other words, using the right frame allows one to understand the situation and prevent conflicts on the wrong target, waste of time and inefficient investments. Using the right frame is a very useful cognitive skill for all operators in the energy supply chain.

And we come to the meso approaches, those placed between very strong organisations such as multinational energy companies or the State, often owner of the same companies. The meso approaches are based on the theory of organisational fields and on that of networks. The watchwords are borders in the first case and bridges in the second. According to organisational theories, there is a continuous work of building and maintaining borders; this process is called lockin, self-referencing, autopoiesis, to make rather than to buy.

What happens with organisational fields that become too closed? There is a need to create bridges, connections, channels of dialogue and exchange with other clusters. Therefore, procedures, figures or organisations emerge that are responsible for establishing bridges. According to a famous

\footnotetext{
${ }^{2}$ In fact, referencing the work of Smith et al. (2005), Markard and Truffer (2008) argue that 'meso level frameworks for the study of technological transitions tend to downplay the importance of agency' (p. 462).
} 
expression of Granovetter (1973), they are bridging or weak ties, such as communications companies, brokerage offices or people on the margins. All of these have ease of establishing relationships with other organisations closed in their core business and internal languages.

The example does not seem risky, but Geels' multi-level perspective or transition model can be inserted in this approach (Geels, 2002; Geels et al., 2016). The problem consists in passing an innovation from one level to another in a situation in which niches, regimes and landscapes - every kind of bordered field - tend to be rigid and not communicating, even if shared by many people. In this case the social sciences, in particular the communicative sciences, play an intermediary role between systems. The examples are very concrete in the energy sector: they are scientific dissemination agencies, cooperatives that mediate between local populations and authorities, participatory platforms and public relations offices of large companies. Thus, the position of social sciences is in this case in-between stronger knowledges and organisations.

Finally, there are the micro models, those referring to the behaviour and attitudes of single individuals in the face of the energy issue. Consumers are generally thought of, but these behavioural or actor-centred approaches are also applicable to business executives, administrators and technicians. The most famous model was called ABC: antecedents, behaviour, consequences (Bijou et al. 1968). More elaborate than the stimulus-response but substantially based on the same assumptions, subjects seek gratifications; if they receive them, they react positively and acquire a conditioned response.

The most sophisticated version of this model is the nudge approach, which envisages providing stimuli at a cognitive level such as information, recognition, the need for emulation or competition (Hoppe \& de Vries, 2019). This approach has inspired intervention policies based on incentives and rewards. Strategic behaviour theories are also attributable to these micro approaches. They add to the stimuli the calculations and predictions that the subject makes of the behaviour of others. The best known case is the prisoner's dilemma. In absence of information on other's intentions, the best strategy is to defect.

Both nudge approaches and those that simulate strategic behaviour are positioned low in the table because they provide useful suggestions to other systems of knowledge and decisions on how to build policies. The followers of these approaches end up being consultants to governments or large companies, the only ones capable of adopting large-scale policies for consumers and employees.

This, therefore, would be the meta-frame, a scheme that is certainly not exhaustive (for example, social practices - a mix of routines and choices - are not contemplated), but which gives serenity to the researcher of the social sciences. The social researcher is not only a consultant at the service of others (microlevel), not even a facilitator or an agit-prop (meso level), not just a visionary who traces utopian world scenarios (macro level). Rather, the social researcher must play all three of these roles. Moreover, many actions depend on how other experts view and place social scientists. Just as social scientists are flexible and play multiple roles, so too should their interlocutors; sometimes, experts must be ready to accept a social frame in which their knowledge of physics is included or it can be at the same level of other ones. Nevertheless, mental flexibility and the ability to frame the phenomena broadly are not enough. We also need for sociology and other social sciences innovative skills, leadership, early prognosis. This cannot be commanded; it springs from the researcher's intuitions, from intense readings, from immersion in daily social realities, in physical contact with other people and landscapes. 
For this task, the proposal is to adopt the term 'energy socialisation', which has been applied to the water issues (Osti, 2020), with which energy has many similarities. It is always about flows. Socialisation refers to two aspects: the learning of ways of living in a society, the sharing of goods or services ${ }^{3}$. For the first aspect, there are socialisation agencies and practices (AguirreBielschowsky et al., 2018), and for the second a variety of arrangements, such as car sharing and car-pooling, which connect to energy consumption. More structured examples of socialisation as sharing are energy cooperatives and energy communities, which comprise an immense literature themselves (Pellizzoni, 2018).

Socialisation would be a master frame simply because of the semi-invisible nature of energy. That makes it the prerogative of only expert knowledge and those who govern it, a sphere completely delegated to complex, auto-poietic, closed systems. This is what we notice precisely for the organisation of high-tech energy systems. Ordinary people are completely de-socialised of the topic.

To overcome the invisibility of energy and the closure of human energy systems, much socialisation is needed to be developed at all the indicated levels, from the macro- to the meso- and up to the micro-level. Our expertise can fulfil this task by highlighting the educational needs of both technicians and consumers. When the investigation techniques themselves become educational tools, we can think, for example, of serious games, which we learn by playing.

At the same time, the socialisation of the means of energy production, to put it in Marxist terminology, is another important task. In this case, energy sharing has the advantage of measurability and division between users, which makes it an easily marketable and then consumable good. But the market as a means of allocating resources fails when it is more convenient to produce and consume the goods together, such as certain forms of energy storage on a residential block (Bögel et al., in press) or the coordination among final users to avoid demand peaks or energy exchanges among rich and poor users. Let's imagine a condominium or a block in which the inhabitants exchange energy not only based on how much they produce individually, but based on the variable needs of each household. These are example of energy socialisation as mutual and coordinated exchange.

The root of the word 'socialisation' is the same as social sciences and sociology. This is our modest gift to the cause of energy transition. But, for the gift is profitable, the two meanings of socialisation must stay together. They work well when awareness - the cognitive dimension - goes hand in hand with the material sharing of energy production, distribution and consumption.

\footnotetext{
${ }^{3}$ There is indeed a third aspect mentioned in literature: Li \& Yilmaz (2019). An interesting debate in social sciences is about differences between socialisation and education (see Mannheim \& Stewart, 1997). The former process tends to reproduce society giving to younger generations the actual values and norms (adaptation), the latter is the achievement of creative attitudes (freedom). The issue, translated in the energy field, drives to learning methods respectful for human innovation capacity.
} 


\section{References}

Aguirre-Bielschowsky, I., Lawson, R., Stephenson, J., \& Todd, S. (2018). Kids and kilowatts: Socialisation, energy efficiency, and electricity consumption in New Zealand. Energy Research \& Social Science, 44, 178-186. https://doi.org/10.1016/j.erss.2018.04.020

Benford, R. D. (2013). Master frame. In D. A. Snow, D. della Porta, B. Klandermans, \& D. McAdam (Eds.), Wiley-Blackwell encyclopedia of social and political movements. Wiley-Blackwell. https://doi.org/10.1002/9780470674871.wbespm126

Bijou, S. W., Peterson, R. F., \& Ault, M. H. (1968). A method to integrate descriptive and experimental field studies at the level of data and empirical concepts. Journal of Applied Behavior Analysis, 1 , $175-191$.

Bögel, P. M., Upham, P., Shahrokni, H., \& Kordas, O. (in press). What is needed for citizen-centered urban energy transitions: Insights on attitudes towards decentralized energy storage. Energy Policy.

Boudon, R., \& Bourricaud F. (1991). Dizionario critico di sociologia. Armando.

Bridge, G., Barca, S., Özkaynak, B., Turhan E., \& Wyeth R. (2018). Towards a political ecology of EU energy policy. In C. Foulds \& R. Robison (Eds.), Advancing energy policy: Lessons on the integration of social sciences and humanities (pp. 163-175). Springer. https://doi.org/10.1007/978-3-319-99097-2_11

Dépelteau, F. (2013). What is the direction of the 'relational turn'? In C. J. Powell \& F. Dépelteau (Eds.), Conceptualizing relational sociology: Ontological and theoretical issues (pp. 163-185). Palgrave Macmillan. https://doi.org/10.1057/9781137342652_10

Dunlop, T. (2019). Mind the gap: A social sciences review of energy efficiency. Energy Research and Social Science, 56, 1-12. https://doi.org/10.1016/j.erss.2019.05.026

Eder, K. (1990). The rise of counter-culture movements against modernity: Nature as a new field of class struggle. Theory, Culture and Society, 7(4), 21-47. https://doi.org/10.1177\%2F026327690007004002

Geels, F. W. (2002). Technological transitions as evolutionary reconfiguration processes: A multi-level perspective and a case-study. Research Policy, 31(8), 1257-1274. https://doi.org/10.1016/S00487333(02)00062-8

Geels, F. W., Berkhout, F., \& van Vuuren, D. (2016). Bridging analytical approaches for low-carbon transitions. Nature Climate Change, 6, 576-583. https://doi.org/10.1038/nclimate2980

Granovetter, M.S. 1973, The Strength of Weak Ties, American Journal of Sociology, 78 (6), 1360-1380

Hara, K., Uwasu, M., Kobayashi, H., Kurimoto, S., Yamanaka, S., Shimoda, Y., \& Umeda, Y. (2012). Enhancing meso level research in sustainability science - Challenges and research needs.

Sustainability, 4, 1833-1847. https://doi.org/10.3390/su4081833

Hoppe, T., \& de Vries, G. (2019). Social innovation and the energy transition. Sustainability, 11(1), 141. https://doi.org/10.3390/su11010141

Ingeborgrud, L., Heidenreich, S., Ryghaug, M., Skjølsvold, T. M., Foulds, C. Robison, R., Buchmann, K., Mourik R. (2020). Expanding the scope and implications of energy research: A guide to key themes and concepts from the Social Sciences and Humanities, Energy Research \& Social Science. 63, 101398, https://doi.org/10.1016/j.erss.2019.101398.

Li, X., \& Yilmaz, S. (2019). China's climate socialisation and renewable energy coalition building. Chinese Journal of Population Resources and Environment, 17(3), 203-216. https://doi.org/10.1080/10042857.2019.1650246

Mannheim, K., \& Stewart, W. A. C. (1962). An introduction to the sociology of education. Routledge.

Markard, J., \& Truffer, B. (2008). Actor-oriented analysis of innovation systems: Exploring micro-meso level linkages in the case of stationary fuel cells. Technology Analysis and Strategic Management, 20(4), 443-464. https://doi.org/10.1080/09537320802141429 
Osti, G. (2019). Above, Beside, Under: Three Ways Social Technical Disciplines Can Work Together in the Energy Transition, in P. Giardullo, L. Pellizzoni, S. Brondi, eds, Connecting Dots: Multiple Perspectives on Socio-technical Transition and Social Practices. Tecnoscienza, 10(2) 127-139

Osti, G. (2020). Water socialisation. In search of a master frame. Rassegna Italiana di Sociologia, 61(2), 229-252. https://doi.org/10.1423/97799

Pellizzoni, L. (2018). Energia di comunità. Una ricognizione critica della letteratura. In G. Osti \& L. Pellizzoni (Eds.), Energia e innovazione tra flussi globali e circuiti locali (pp. 17-41). EUT.

Pesch, U., Correljé, A., Cuppen, E. Taebi, B. (2018). Energy justice and controversies: Formal and informal assessment in energy projects, Energy Policy, 109, 825-834.

Reid, L., Sutton, P., \& Hunter, C. (2010). Theorizing the meso level: The household as a crucible of proenvironmental behaviour. Progress in Human Geography, 34(3), 309-327. https://doi.org/10.1177\%2F0309132509346994

Schenk, N. J., Moll, H. C., \& Schoot Uiterkamp, A. J. (2007). Meso-level analysis, the missing link in energy strategies. Energy Policy, 35(3), 1505-1516. https://doi.org/10.1016/j.enpol.2006.04.013

Schütz, A. (1962). Collected Papers I: The Problem of Social Reality. Edited by Maurice Natanson. Martinus Nijhoff.

Smith, A., Stirling, A., \& Berkhout, F. (2005). The governance of sustainable socio-technical transitions. Research Policy, 34(10), 1491-1510. https://doi.org/10.1016/j.respol.2005.07.005

Sovacool, B., Hess D. J. (2017). Ordering theories: Typologies and conceptual frameworks for sociotechnical change. Social Studies of Science, 47(5) 703-750. https://doi.org/10.1177/0306312717709363

Sovacool, B., Hess, D. J., Amir, S., Geels, F. W., Hirsh, R., Rodriguez Medina, L., Miller, C., Alvial Palavicino, C., Phadke, R., Ryghaug, M., Schot, J., Silvast, A., Stephens, J., Stirling, A., Turnheim, B., van der Vleuten, E., van Lente, H., \& Yearley, S. (2020). Sociotechnical agendas: Reviewing future directions for energy and climate research. Energy Research and Social Science, 70, 1-35. https://doi.org/10.1016/j.erss.2020.101617

Spreng, D. Flüeler, T., Goldblatt, D. L. \& Minsch, J. (2012) (eds.). Tackling Long-Term Global Energy Problems, Environment \& Policy, Springer 